\title{
Cobalt and nickel uptake by silica-based extractants
}

Article

Accepted Version

Pepper, S. E., Whittle, K. R., Harwood, L. M., Cowell, J., Lee, T. S. and Ogden, M. D. (2018) Cobalt and nickel uptake by silica-based extractants. Separation Science and Technology, 53 (10). pp. 1552-1562. ISSN 0149-6395 doi:

https://doi.org/10.1080/01496395.2017.1405034 Available at https://centaur.reading.ac.uk/74598/

It is advisable to refer to the publisher's version if you intend to cite from the work. See Guidance on citing.

To link to this article DOI: http://dx.doi.org/10.1080/01496395.2017.1405034

Publisher: Taylor \& Francis

All outputs in CentAUR are protected by Intellectual Property Rights law, including copyright law. Copyright and IPR is retained by the creators or other copyright holders. Terms and conditions for use of this material are defined in the End User Agreement.

\section{www.reading.ac.uk/centaur}

\section{CentAUR}

Central Archive at the University of Reading 
Reading's research outputs online 


\title{
Cobalt and nickel uptake by silica-based extractants
}

\author{
Sarah E. Pepper ${ }^{1}$, Karl R. Whittle ${ }^{2}$, Laurence M. Harwood ${ }^{3}$, Joseph
}

Cowell ${ }^{3}$, Taek Seung Lee ${ }^{4}$ and Mark D. Ogden ${ }^{1}$

${ }^{1}$ Separations and Nuclear Chemical Engineering Research (SNUCER), Department of Chemical and Biological Engineering, University of Sheffield, Sheffield, United Kingdom; ${ }^{2}$ School of Engineering, University of Liverpool, Liverpool, United Kingdom;

${ }^{3}$ Department of Chemistry, University of Reading, Reading, United Kingdom;

${ }^{4}$ Department of Organic Materials Engineering, Chungnam National University,

Daejeon, South Korea

Sarah Pepper, Separations and Nuclear Chemical Engineering Research (SNUCER),

Department of Chemical and Biological Engineering, University of Sheffield, Sheffield, S1 3JD, United Kingdom. Email: s.pepper@ sheffield.ac.uk 


\section{Cobalt and nickel uptake by silica-based extractants}

The $\mathrm{pK}_{\mathrm{a}} \mathrm{s}$ of ethyl/butyl phosphonate silica (EBP-Si) have been determined and the removal of cobalt and nickel from solution investigated as a function of various parameters and compared with Purolite S950. pH uptake experiments suggested a combination of ion exchange and acid dissociation of the surface occurring. Isotherm data, fitted using Langmuir and Dubinin-Radushkevich models, indicated that stronger complexes formed with S950 than EBP-Si. Kinetic data, fitted using a pseudo second-order model, suggested that the ratedetermining process is the reaction of metal ions with the chelating functionality of the resin. Uptake by EBP-Si is 2-3 times faster than on S950.

Keywords: ion exchange; silica-based resin; Purolite S950; cobalt; nickel

\section{Introduction}

Heavy metals like cobalt and nickel are commonly found in contaminated water from many industrial operations, such as mining operations, metal plating facilities, battery and catalyst production as well as nuclear power plant operation. These, and other metals such as lead, chromium, mercury and cadmium, are not biodegradable and are toxic and harmful (and possibly radioactive), even at low concentrations, to human health, aquatic life and the environment. ${ }^{[1,2]}$ Consequently, the recovery of these metals has received considerable attention. ${ }^{[3-12]}$

Solvent extraction and ion exchange are the two most common techniques employed for the removal of metals from an aqueous system. ${ }^{[5,13-17]}$ With respect to ion exchange, there has been a significant body of research investigating the use of organofunctionalised molecules immobilised on a solid support, with polystyrene-DVB-based materials and silica among the most popular materials. ${ }^{[3,4,8-10]}$ The absorption mechanism has been reported to occur through a combination of ionic and coordinating interactions, instead of via simple electrostatic interactions as in conventional ion exchange. ${ }^{[18]}$ This means that these chelating resins offer greater selectivity than 
conventional resins. ${ }^{[19]}$ However, polymeric-based resins can display slow kinetics, may swell, be sensitive to chemical environments and lose mechanical stability. ${ }^{[20]}$ Silicabased resins do not have these drawbacks and, importantly, can be thermally treated. ${ }^{[20]}$

A wide range of organic materials have been attached to silica for the recovery of metals. Some examples include 1,8-dihydroxyanthraquinone for $\mathrm{Fe}(\mathrm{III}), \mathrm{Co}(\mathrm{II})$, $\mathrm{Ni}(\mathrm{II})$ and $\mathrm{Cu}(\mathrm{II})$ recovery, ${ }^{[21]}$ imidazole, diaza-18-crown-6 and dibenzo-18-crown-6 for Co(II) sorption, ${ }^{[8]}$ murexide for U(VI) preconcentration, ${ }^{[11]}$ salicylaldoxime for Co(II), $\mathrm{Ni}(\mathrm{II}), \mathrm{Co}(\mathrm{II}), \mathrm{Zn}$ (II) and $\mathrm{Fe}(\mathrm{III})$ preconcentration ${ }^{[7]}$ and gallic acid for $\mathrm{Pb}$ (II), $\mathrm{Cu}(\mathrm{II})$, $\mathrm{Cd}(\mathrm{II})$ and $\mathrm{Ni}(\mathrm{II})$ preconcentration. ${ }^{[9]}$ Additionally, there are many commercially available polymeric-based resins and several silica-based resins that have been used to remove or recover a range of metal ions. ${ }^{[3,4,10,19,22-27]}$

In the nuclear industry a range of ion exchange materials are used to treat various water streams, from primary water coolant purification to fuel storage pond water treatment to drainage water treatments. Ion exchange resins are regenerated and used until no longer practical and after this point are stored and/or disposed of. Often, the spent resins are highly radioactive and must be treated prior to disposal. Due to the high costs associated with disposal, the material often undergoes a process of volume reduction. Techniques such as dewatering, pyrolysis and stripping may reduce the category of the resin waste, for example from high level waste to intermediate or low level waste, but may generate a quantity of highly active waste that must be separately treated. ${ }^{[28-31]}$ In the United Kingdom, currently the preferred option for high level radioactive waste disposal is vitrification within a borosilicate matrix and long-term storage (potentially thousands of years) of the glass-based waste form. ${ }^{[32]}$ As mentioned above, one potential advantage of silica-based resins lies in their ability to be thermally treated. As silica-based resins already contain silica, it is hoped that these materials 
could be utilised to remove metals from the waste stream and then directly converted to a borosilicate-based wasteform.

In this paper, presenting results from our initial experiments, we have focused on cobalt and nickel, as important heavy metal pollutants found in the aqueous waste streams of both conventional and nuclear industries. The uptake of these metals by a silica-based resin ethyl/butyl phosphonate silica (PhosphonicS PO1) was compared with a polymeric-based resin with similar functionality, Purolite S950 (Purolite), an aminophosphonic acid on macroporous polystyrene crosslinked with DVB (Figure 1). The $\mathrm{pK}_{\mathrm{a}}$ of EBP-Si has also been determined by acid-base titration. The loading behaviour of cobalt and nickel was investigated as a function of $\mathrm{pH}$ and metal concentration. The kinetics of metal uptake were also examined. The equilibrium data obtained were then analysed using the Langmuir and Dubinin-Radushkevich (D-R) isotherms and the kinetic data were fitted using a pseudo-second order model.

Both resins are commercially available but to the best of our knowledge, this is the first time that partitioning of metals to ethyl/butyl phosphonate silica has been reported and compared with a macroporous polystyrene DVB resin with a thorough comparison of the thermodynamic and kinetic parameters. Additionally, this study represents the first in a series of papers investigating the use of silica-based resins for the removal of metals from aqueous wastes and their potential for direct conversion to a glass-based wasteform.

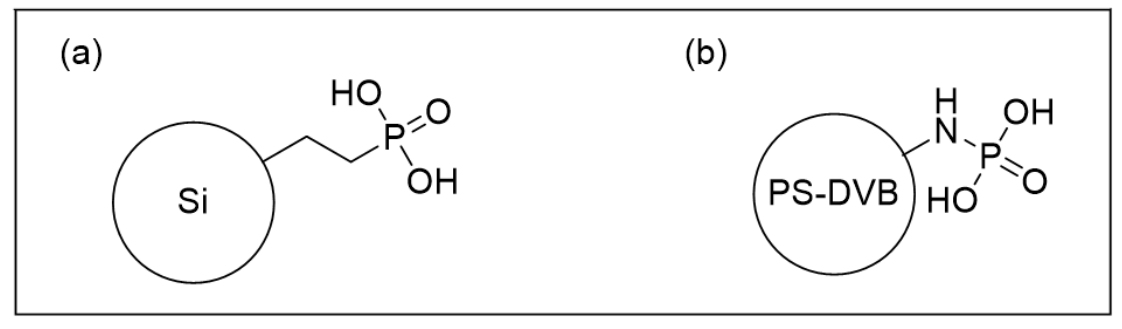

Figure 1. The structure of (a) ethyl/butyl phosphonate silica and (b) Purolite S950. 


\section{Experimental}

\section{Materials}

All chemicals used were of analytical grade or better and supplied by SigmaAldrich unless otherwise specified. Sodium ethyl/butyl phosphonate silica (PhosphonicS PO1) was purchased directly from PhosphonicS, while Purolite S950 was kindly donated by Purolite. Both resins were converted from their sodium forms to their protic forms by contact with a solution of $1 \mathrm{M}$ hydrochloric acid for 24 hours. After this time, the resins were washed twice with deionised water (DI water) and stored as a suspension under DI water.

Stock solutions of $\mathrm{Co}(\mathrm{II})$ and $\mathrm{Ni}(\mathrm{II})$ were prepared by dissolving their respective chloride salts in DI water. Cobalt and nickel analysis was carried out using either a Perkin Elmer Atomic Absorption Spectrometer AAnalyst 400 or a Thermo Scientific iCAP 6000 series ICP-OES. Calibration for both instruments was performed using standard solutions (Inorganic Ventures) diluted with 1\% nitric acid.

\section{Determination of acid dissociation constants for EBP-Si}

The acid dissociation constants of EBP-Si were determined using an adapted version from Jarvis and Wagener. ${ }^{[33]}$ An aliquot of the protonated form of the resin was combined with $0.01 \mathrm{M}$ hydrochloric acid and titrated with standardized $\mathrm{NaOH}$ $(0.099293 \mathrm{M})$. The titration was carried out by small incremental additions from a 10 $\mathrm{mL}$ burette. After each addition of base, the $\mathrm{pH}$ was recorded after a stable period of response, which was achieved within 5 to 10 minutes. The electrode used was a Mettler Toledo triple junction glass electrode with $3 \mathrm{M} \mathrm{NaCl}$ as the filling solution. The experimental and titration solutions contained sufficient $\mathrm{NaCl}$ to bring the ionic strength 
to $1 \mathrm{M}$ and the temperature was maintained at $21{ }^{\circ} \mathrm{C}$. The potentiometric titrations were performed in triplicate in a static fashion.

The concentration of proton exchange groups on the silica material was determined by contacting an aliquot of the sodium form of the resin (disodium ethyl/butyl phosphonate silica) with $0.01 \mathrm{M}$ hydrochloric acid until thermodynamic equilibrium was reached ( 24 hours). The concentration was then determined by the difference in proton concentration per mass of resin. This was also performed in triplicate.

The potentiometric curves produced were fitted using PSEQUAD. ${ }^{[34]}$ PSEQUAD is a comprehensive program for the evaluation of potentiometric and/or spectrophotometric equilibrium data using analytical derivatives. The calculation of the unknown free concentrations of components is based on the standard Newton-Raphson procedure by minimizing the difference between calculated and experimental data points for a given number of species affecting free proton in solution. The GaussNewton method is used for the refinement of these parameters. ${ }^{[35]}$ This makes the program capable of fitting polyelectrolytes and solid-liquid systems including metal ion precipitation.

\section{Metal loading experiments as a function of $\mathrm{pH}$ and metal concentration}

An aliquot of wet settled resin $(1.6 \mathrm{~mL})$ was contacted with a known volume of solution containing $\mathrm{Co}$ and $\mathrm{Ni}$ set at an initial $\mathrm{pH}$ and shaken on a mechanical shaker for 24 hours. The ratio of $\mathrm{Co}$ and $\mathrm{Ni}$ was kept constant at 1:1 and the $\mathrm{pH}$ was initially set using dilute solutions of hydrochloric acid, however, no attempt was made to control the $\mathrm{pH}$ during the experiment. The solid was allowed to settle under gravity, which usually took one minute or less, after which time the solution $\mathrm{pH}$ was measured and an aliquot of the solution taken for elemental analysis. 
Extraction efficiency and distribution ratio, $K_{d}$, were calculated as follows:

$$
\begin{aligned}
& E \%=\left(\frac{c_{0}-c_{f}}{c_{0}}\right) \times 100 \% \\
& K_{d}=\left(\frac{c_{0}-c_{f}}{c_{f}}\right) \times \frac{V}{m}
\end{aligned}
$$

Where $c_{0}$ and $c_{f}$ denote the initial (pre-contact) and final (post contact) metal concentrations, respectively, $V$ represents the volume of solution in contact with the resin and $m$ is the mass of resin. The mass of resin was calculated by converting the volume of wet settled resin using the experimentally determined resin densities for each preconditioned material; $0.498 \mathrm{~g} \mathrm{~mL}^{-1}$ and $0.378 \mathrm{~g} \mathrm{~mL}^{-1}$ for H-EBP-Si and S950 respectively.

The effect of metal concentration (isotherm experiments) was determined in a similar manner to that described above, except that the $\mathrm{pH}$ value was set at an initial value and the amount of metal added was varied. As before the ratio of cobalt to nickel was constant at 1:1.

\section{Static kinetic tests}

The kinetics of uptake were determined by contacting an aliquot of wet settled resin $(1.6 \mathrm{~mL})$ with a solution containing $\mathrm{Co}$ and $\mathrm{Ni}$ set at an initialpH and shaken on a mechanical shaker for up to 1 week. The solid to solution ratio was such that aliquots removed for analysis were less than $10 \%$ of the solution volume to avoid dilution effects. Samples were removed and analysed at various time intervals over the course of a week using a similar procedure to the one described above. 


\section{Results and Discussion}

\section{Determination of acid dissociation constants}

The averaged triplicate titration curve for EBP-Si at $1 \mathrm{M} \mathrm{NaCl}$ ionic strength is shown in Figure 2 and the values for the proton dissociation constants fit using PSEQUAD are presented in Table 1. Best fit of the titration data was carried out by incorporating 3 protonated species on the surface of the resin with a total acid concentration of $0.0269 \mathrm{M}$ in a volume of $25.00 \mathrm{~mL}$ and total proton exchange capacity determined at $0.00195 \mathrm{M}$.

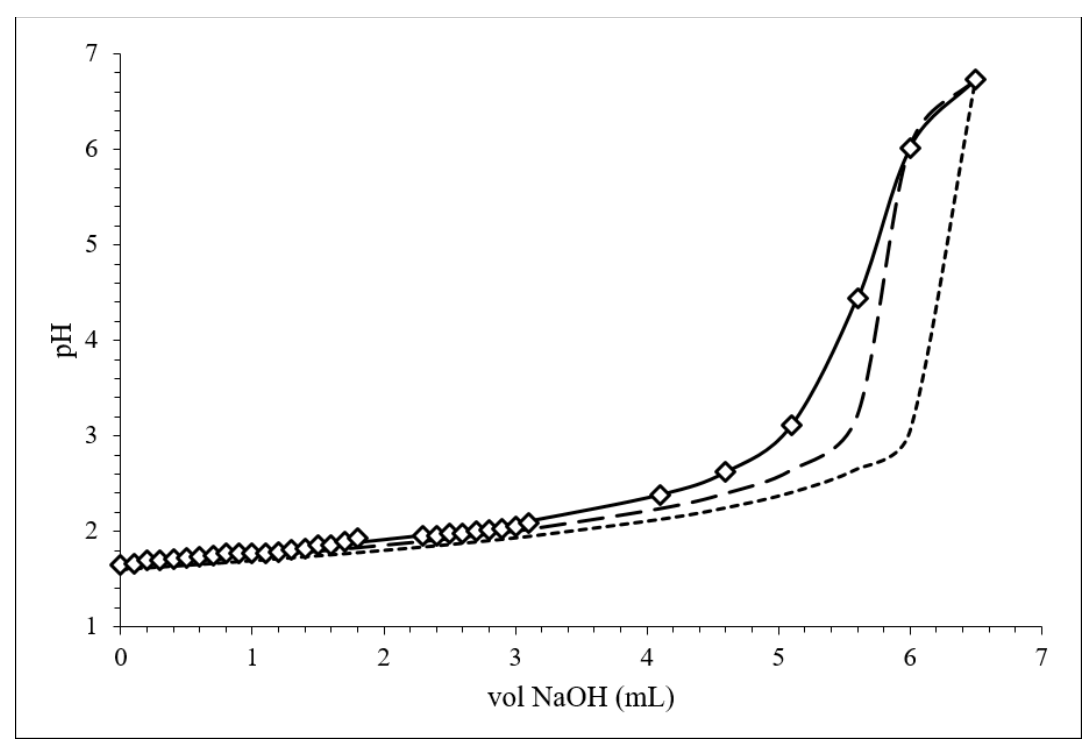

Figure 2. Potentiometric titration of EBP-Si at $21{ }^{\circ} \mathrm{C}$ and $\mathrm{I}=1 \mathrm{M}(\mathrm{NaCl})$. Diamonds $=$ experimental data points. PSEQUAD program fits are shown by black lines: solid line = $3 \mathrm{pK}_{\mathrm{a}}$ fit, dashed line $=2 \mathrm{pK}_{\mathrm{a}}$ fit, dotted line $=1 \mathrm{pK}_{\mathrm{a}}$ fit.

A titration model considering a singly charged protonated species, HL, present on the resin surface and the presence of two species, $\mathrm{HL}$ and $\mathrm{H}_{2} \mathrm{~L}$, resulted in overall poor fitting of the potentiometric titration curve by over predicting free proton in solution. The best fit was obtained by including 3 protonation species into the titration curve, resulting in $2 \mathrm{pK}_{\mathrm{a}}$ values that are very close to each other at $6.46( \pm 0.03)$ and 
$6.38( \pm 0.06)$ and a more acidic $\mathrm{pK}_{\mathrm{a}}$ at $4.22( \pm 0.04)$. Incorporation of $\mathrm{HL}_{2}$ and $\mathrm{H}_{2} \mathrm{~L}_{2}$ was also tested but produced significantly poorer fits. Additionally, a model using four $\mathrm{pK}_{\mathrm{a}}$ values was tested and although a reasonable fit was obtained, it led to very high errors in the calculated acid dissociation constants by orders of magnitude and was thus discarded.

Table 1. Best fit dissociation constants for EBP-Si at $21^{\circ} \mathrm{C}$ and $\mathrm{I}=1 \mathrm{M}(\mathrm{NaCl})$ determined using PSEQUAD. ${ }^{[29]}$

\begin{tabular}{cccc}
\hline Species & MHL notation & $\log _{10} \beta$ & $\log _{10} \mathrm{~K}$ \\
\hline $\mathrm{HL}$ & 011 & $6.46 \pm 0.03$ & \\
$\mathrm{H}_{2} \mathrm{~L}$ & 021 & $12.84 \pm 0.06$ & $6.38 \pm 0.06$ \\
$\mathrm{H}_{3} \mathrm{~L}$ & 031 & $17.06 \pm 0.04$ & $4.22 \pm 0.04$ \\
\hline
\end{tabular}

Phosphonate $\left((\mathrm{HO})_{2} \mathrm{P}(\mathrm{O}) \mathrm{H}\right)$ has been reported to have two $\mathrm{pK}_{\mathrm{a}}$ values at 1.42 and 6.7. ${ }^{[36]}$ In our experiments, the $\mathrm{pK}_{\mathrm{a}}$ determination was carried out at an initial $\mathrm{pH}$ value of 2 hence why it was not determined. However, the $\mathrm{pK}_{\mathrm{a}}$ values at 6.46 and 6.38 are close to the value for phosphonate at 6.7. The values may be lower as a result of the attachment of the phosphonate group to the silica surface as it has been reported that attaching a ligand to a surface lowers the $\mathrm{pK}_{\mathrm{a}}$ value. ${ }^{[33,37]}$ The presence of two $\mathrm{pK}_{\mathrm{a}}$ values close together implies heterogeneity on the functionalised surface. The value at 4.22 may be associated with the silanol group of the silica surface, which has a reported $\mathrm{pK}_{\mathrm{a}}$ value of 4.5. ${ }^{[38]}$ As before, the hydrophobic environment of the functionalised silicate surface leads to the acidification of the silanol group $\mathrm{pK}_{\mathrm{a}}$. 


\section{Effect of pH}

The $\mathrm{pH}$ was varied from 0 to 5 for H-EBP-Si and 2 to 5 for S950. Experiments were not performed below $\mathrm{pH} 2$ for $\mathrm{S} 950$ as it has been reported that uptake of divalent cations is not observed below this $\mathrm{pH} \cdot{ }^{[4]}$ Results are shown in Figure 3 and are presented as a function of equilibrium $\mathrm{pH}$.

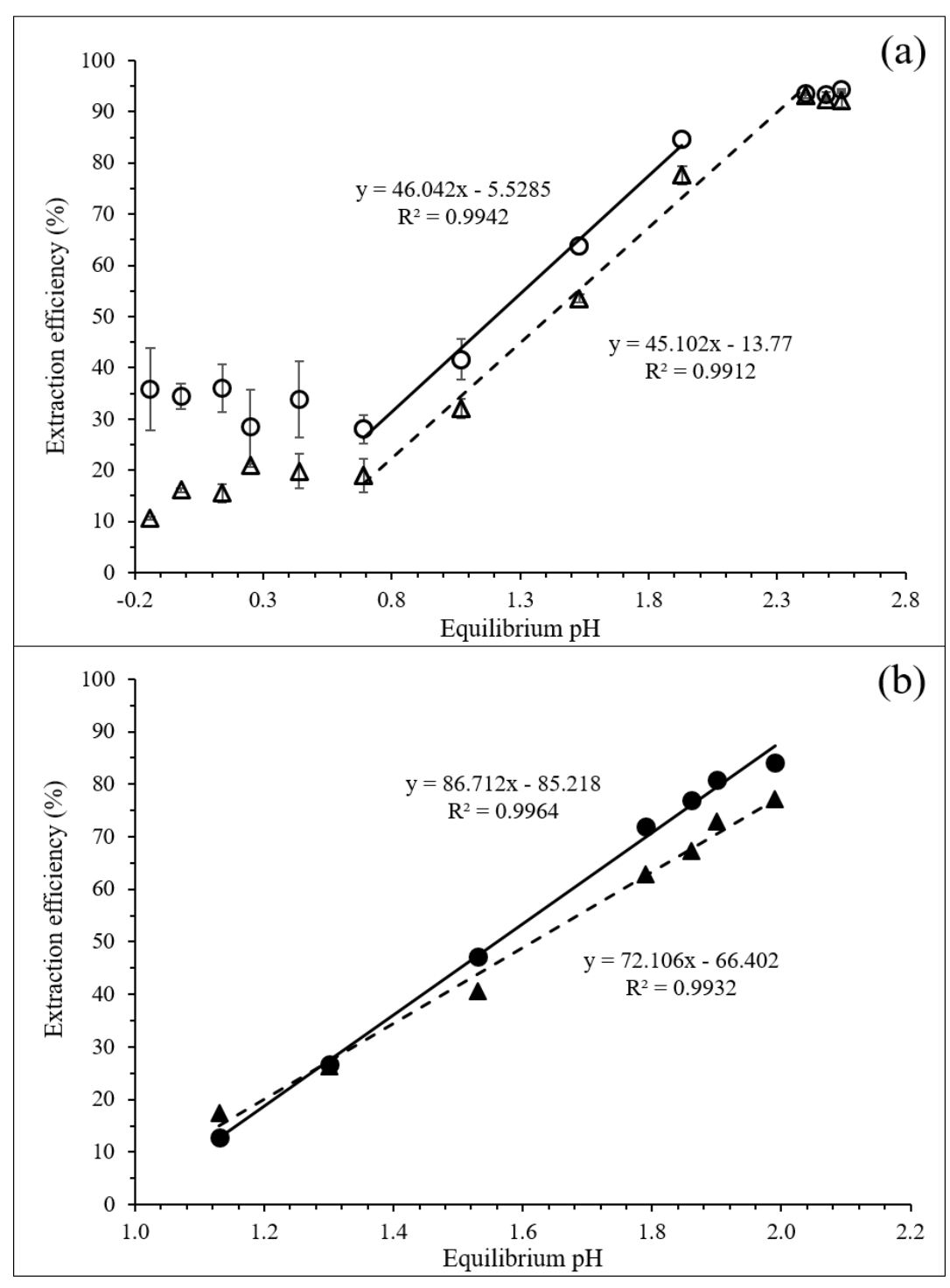

Figure 3. Percentage metal uptake as a function of $\mathrm{pH}$ for cobalt and nickel on (a) EBP$\mathrm{Si}$ and (b) S950 at $21{ }^{\circ} \mathrm{C}$ and $24 \mathrm{hr}$. contact time. Circles $=\mathrm{Co}^{2+}$ and triangles $=\mathrm{Ni}^{2+}$, black solid line $=\mathrm{Co}^{2+}$, black dashed line $=\mathrm{Ni}^{2+}$. 
Uptake of both metals by EBP-Si appears to be initially constant at approximately $32 \%$ and $17 \%$ for $\mathrm{Co}(\mathrm{II})$ and $\mathrm{Ni}(\mathrm{II})$ respectively. At lower acidic $\mathrm{pH}$ values it may be expected that extraction of $\mathrm{Co}(\mathrm{II})$ and $\mathrm{Ni}$ (II) decreases as competition for the phosphonate group between the metals and protons increases. Moderate uptake at lower $\mathrm{pH}$ values indicates a surface affinity for $\mathrm{Co}(\mathrm{II})$ over $\mathrm{Ni}(\mathrm{II})$ whereby extraction occurs without the exchange of protons. This is an adsorption process that may be indicative of an extraction mechanism via adduct formation with a neutral metal species. ${ }^{[39]}$ This potential extraction mechanism is further supported by the higher affinity of $\mathrm{Co}(\mathrm{II})$ for $\mathrm{Cl}$ - in solution over $\mathrm{Ni}(\mathrm{II}) .{ }^{[40]}$ Above an equilibrium $\mathrm{pH}$ value of 0.5 , the amount of metal increases linearly as a function of $\mathrm{pH}$ until reaching a maximum uptake value, presumably as all metal coordination sites are utilized. A similar experiment was performed with the unconditioned disodium form of the resin and the same trend with $\mathrm{pH}$ was observed (data not shown). However, overall the amount of cobalt and nickel taken up was slightly suppressed compared to the protonated resin by an average of approximately $10-12 \%$. This is due to the strength of the sodium adduct when compared directly with the protonated form of the resin functionality. For S950, uptake increases linearly as a function of $\mathrm{pH}$. As expected, during the course of the experiment, protons were released, resulting in a decrease in $\mathrm{pH}$, as the metals were taken up by both resins. Figure 4 shows the uptake as a function of the difference in proton concentration for EBP-Si. The graph shows that the release of protons corresponds to the uptake of $\mathrm{Co}(\mathrm{II})$ and $\mathrm{Ni}(\mathrm{II})$, which supports the theory that uptake proceeds via an ion exchange mechanism. By taking the gradient of the linear section of the graph, the $\mathrm{pH}$ value corresponding to $50 \%$ uptake was determined. These values are shown in Table 2. 


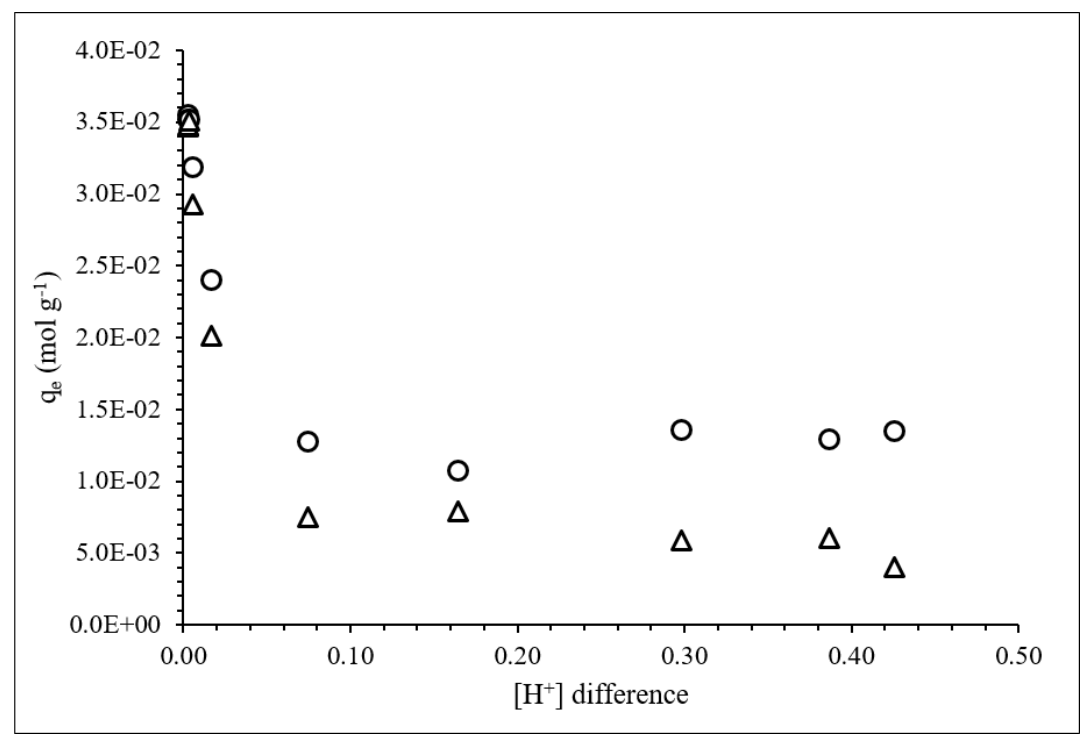

Figure 4. Uptake of cobalt and nickel as a function of difference in proton concentration between initial and equilibrium $\mathrm{pH}$ values. Circles $=\mathrm{Co}^{2+}$ and triangles $=\mathrm{Ni}^{2+}$.

Table 2. Values of $\mathrm{pH}_{50}$ and numbers of protons exchanged for cobalt and nickel extraction by EBP-Si and S950 at $21^{\circ} \mathrm{C}$ and $24 \mathrm{hr}$. contact time. Cobalt and nickel concentrations were constant at a ratio of $1: 1$.

\begin{tabular}{ccccc}
\hline & \multicolumn{2}{c}{$\mathrm{pH}_{50}$} & \multicolumn{2}{c}{ No. protons exchanged } \\
& $\mathrm{Co}^{2+}$ & $\mathrm{Ni}^{2+}$ & $\mathrm{Co}^{2+}$ & $\mathrm{Ni}^{2+}$ \\
\hline $\mathrm{H}-$ EBP-Si & 1.21 & 1.41 & 0.94 & 1.03 \\
$\mathrm{Na-EBP-Si}$ & 1.70 & 1.85 & 1.30 & 1.32 \\
$\mathrm{~S} 950$ & 1.56 & 1.61 & 1.80 & 1.41 \\
\hline
\end{tabular}

$\log K_{d}$ values as a function of $\mathrm{pH}$ for both resins are shown in Figure 5. Both resins display a similar trend in that the value of $K_{d}$ increases with increasing $\mathrm{pH}$, as expected. Also, the values for cobalt are larger than those for nickel. This is similar to results obtained with ES 467, which contains aminomethylphosphonic acid groups anchored on a macroporous polystyrene DVB. ${ }^{[23]}$ The gradient of this graph gives an 
indication of the number of protons exchanged during metal uptake. These values are shown in Table 2 along with the values determined for the unconditioned EBP-Si. With cobalt and nickel, if ion exchange were the only process occurring, it would be expected that 2 protons would be exchanged per cobalt or nickel. However, the values obtained in these experiments are all below the expected value of 2 . As mentioned above, phosphonate has a $\mathrm{pK}_{\mathrm{a}}$ value around 1.42 and therefore the EBP-Si surface may already be negatively charged and consequently the ideal number of protons may not be transferred during $\mathrm{Co}(\mathrm{II})$ and $\mathrm{Ni}(\mathrm{II})$ uptake. Therefore it is likely that there is a combination of ion exchange between the metals and the surface and acid dissociation of the surface occurring.

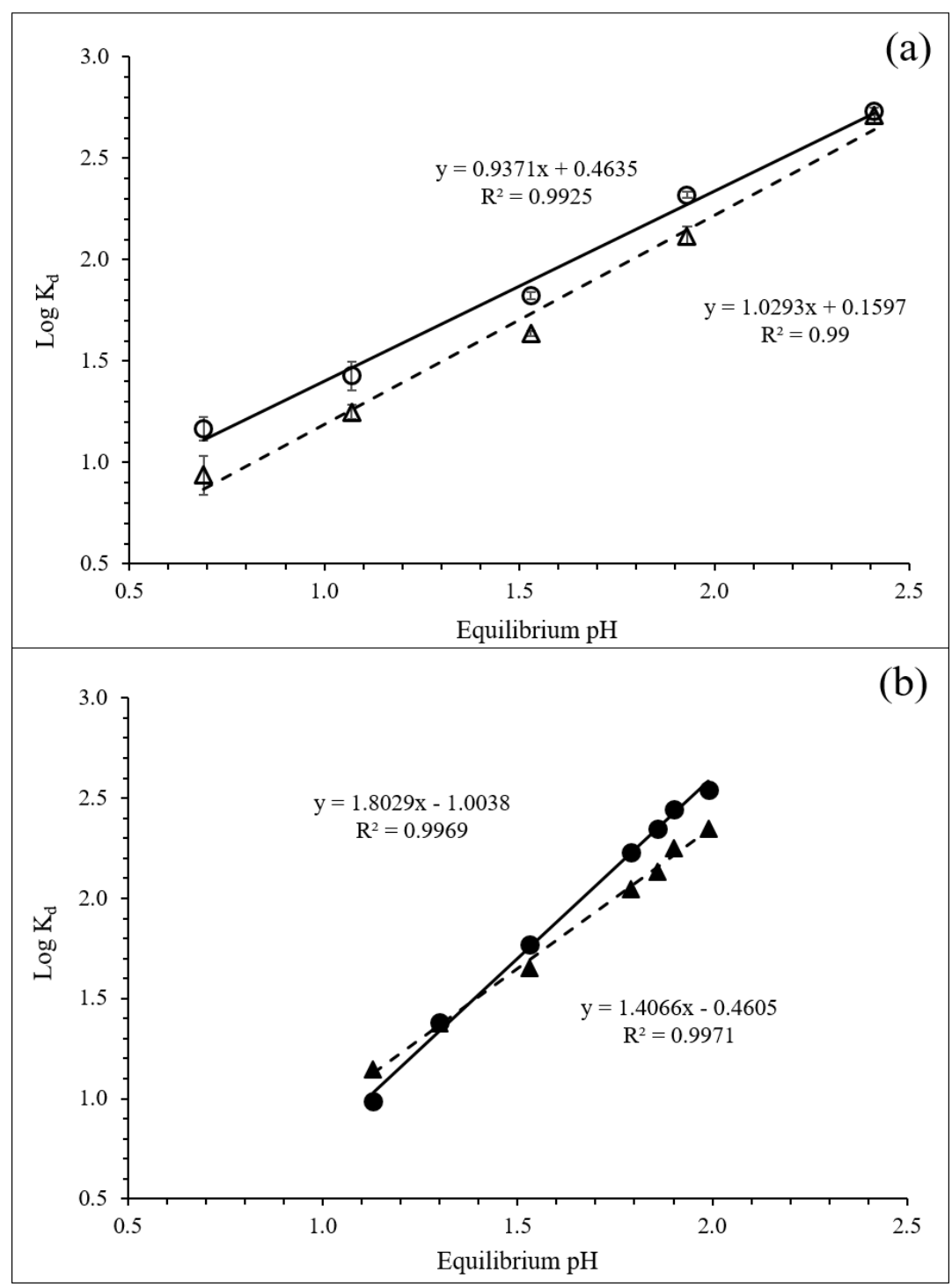


Figure 5. Log distribution ratio as a function of $\mathrm{pH}$ for cobalt and nickel on (a) EBP-Si and (b) S950 at $21{ }^{\circ} \mathrm{C}$ and $24 \mathrm{hr}$. contact time. Circles $=\mathrm{Co}^{2+}$ and triangles $=\mathrm{Ni}^{2+}$, black solid line $=\mathrm{Co}^{2+}$, black dashed line $=\mathrm{Ni}^{2+}$.

\section{Isotherm experiments}

Isotherm experiments were performed at $\mathrm{pH}$ values of 2 and 4.3 for $\mathrm{H}-\mathrm{EBP}-\mathrm{Si}$ and S950, respectively. The results are shown in Figure 6. These $\mathrm{pH}$ values were chosen as they corresponded to the maximum amount of metal taken up by each resin, as determined from the effect of $\mathrm{pH}$ experiments. As expected, increasing metal concentration corresponds to an increase in the amount of metal taken up by the surface up to a maximum concentration, after which uptake remains constant. 


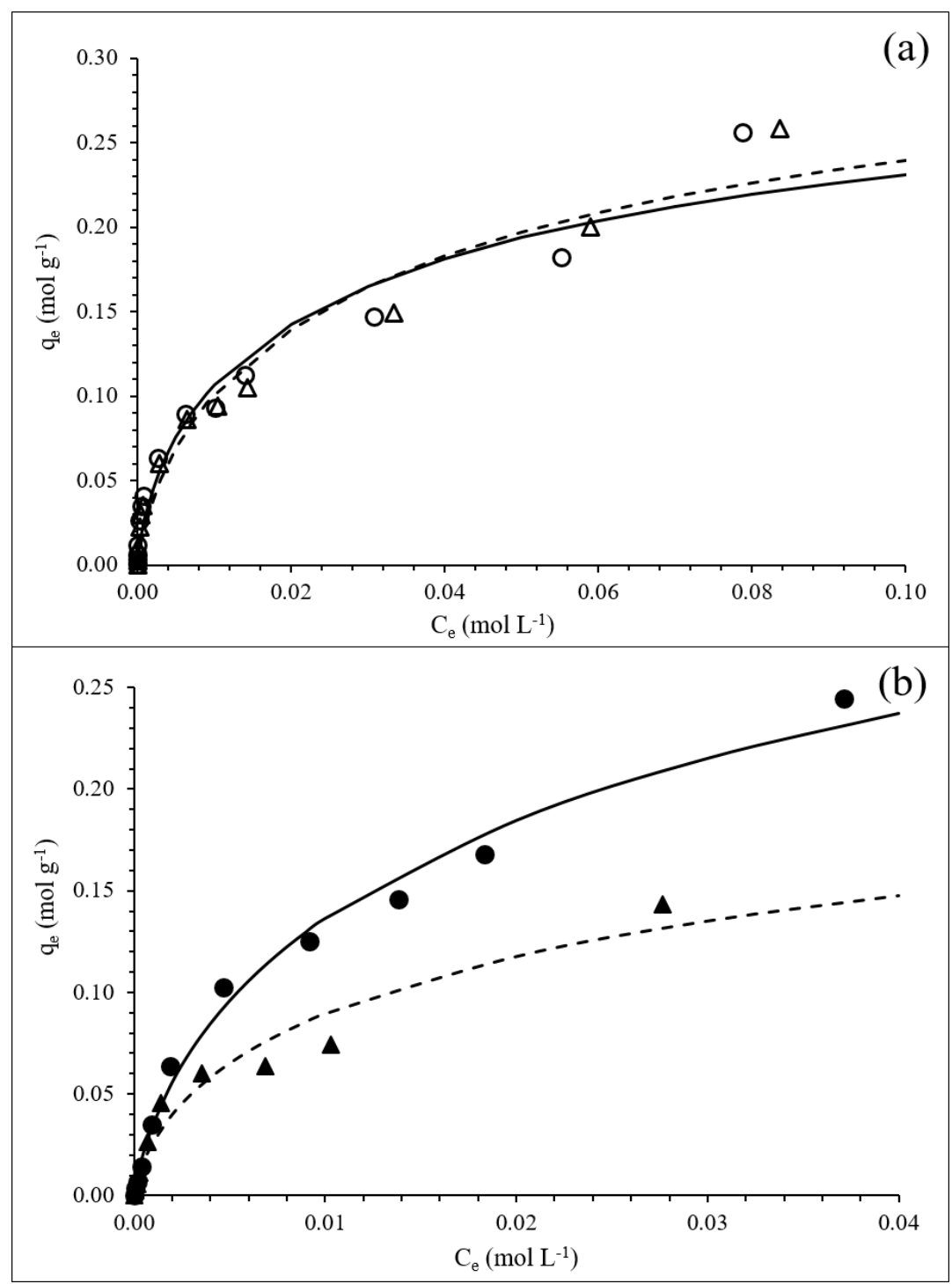

Figure 6. Isotherms for cobalt and nickel uptake on (a) EBP-Si at pH 2.0 and (b) S950 at $\mathrm{pH} 4.3,21^{\circ} \mathrm{C}$ and $24 \mathrm{hr}$ contact fitting using D-R isotherm model. Circles $=\mathrm{Co}^{2+}$ and triangles $=\mathrm{Ni}^{2+}$, black solid line $=\mathrm{Co}^{2+} \mathrm{D}-\mathrm{R}$ fit, black dashed line $=\mathrm{Ni}^{2+} \mathrm{D}-\mathrm{R}$ fit.

The adsorption isotherm models, Langmuir and D-R have been widely utilised to describe the experimental data of sorption isotherms. ${ }^{[35,41,42]}$ The Langmuir isotherm is expressed as:

$$
q_{e}=\frac{q_{m} K_{L} c_{e}}{1+a_{L} c_{e}}
$$

Where $q_{e}$ is the maximum amount of adsorbate in the adsorbant at equilibrium $\left(\mathrm{mol} \mathrm{g}^{-1}\right)$, 
$K_{L}$ is the Langmuir isotherm constant $\left(\mathrm{dm}^{3} \mathrm{~g}^{-1}\right), c_{e}$ is the concentration of adsorbent at equilibrium (mol L-1) and $a_{L}$ is the Langmuir isotherm constant $\left(\mathrm{dm}^{3} \mathrm{~g}^{-1}\right)$. The Langmuir isotherm constant, $K_{L}$ is related to the maximum monolayer coverage capacity, $q_{m}$ (mol $\left.\mathrm{g}^{-1}\right)$ by the following:

$$
q_{m}=\frac{K_{L}}{a_{L}}
$$

The Langmuir isotherm refers to homogeneous adsorption, with each molecule possessing constant enthalpies and sorption activation energies. ${ }^{[41]}$ Since this assumption may not account for the uptake of two metal species by a complexing molecule attached to a resin surface, the data have also been fitted with the D-R isotherm, shown below, which expresses the adsorption mechanism with a Gaussian energy distribution onto a heterogeneous surface: ${ }^{[41]}$

$$
q_{e}=q_{D} \exp \left(-B_{D}\left[R T \ln \left(1+\frac{1}{c_{e}}\right)\right]^{2}\right)
$$

Where $q_{e}$ is the maximum amount of adsorbate in the adsorbant at equilibrium ( $\left.\mathrm{mol} \mathrm{g}^{-1}\right)$, $q_{D}$ is the theoretical isotherm saturation constant $\left(\mathrm{mol} \mathrm{g}^{-1}\right), B_{D}$ is a D-R isotherm constant, $\mathrm{R}$ is the gas constant $\left(8.314 \mathrm{~kJ} \mathrm{~mol}^{-1} \mathrm{~K}^{-1}\right)$, $\mathrm{T}$ is the absolute temperature $(\mathrm{K})$ and $c_{e}$ is the adsorbate equilibrium concentration $\left(\mathrm{mol} \mathrm{L}^{-1}\right)$. The mean free energy of sorption, $E_{D}$, can be calculated from the following:

$$
E_{D}=\frac{1}{\sqrt{B_{D}}}
$$

The fitting for both sorption isotherms was carried out using linear regression and nonlinear least squared analysis using SOLVER. ${ }^{[43]}$ The parameters determined for Langmuir and D-R fits are shown in Table 3. The correlation coefficients for the 
Langmuir approach are very poor, while they were significantly improved for D-R and its fit is shown in Figure 6. It has been shown that $\mathrm{S} 950$ has a heterogeneous surface, ${ }^{[3]}$ as does surface-modified silica. ${ }^{[8,20,44]}$ Consequently, it is not surprising that the Langmuir model, which assumes monolayer adsorption occurring at a fixed number of sites that are identical and equivalent, gives such a poor fit to the data, while the D-R model expresses the adsorption mechanism with a Gaussian energy distribution onto a heterogeneous surface. ${ }^{[1]}$ The D-R parameter $q_{D}$ gives an indication of the maximum sorption capacity of a material and it can be seen that it is roughly four times greater for S950 compared to EBP-Si. This is primarily due to the differences in structure: EBP-Si is a surface functionalised material, while $\mathrm{S} 950$ is a macroporous material that is functionalised both on the surface and on the interior. Therefore, S950 will have more sites available for sorption. These values also suggest that both materials have a higher capacity for nickel than cobalt. This is in agreement with previous studies with surfacefunctionalised silica and S950..$^{[4,10,24,44]}$

Table 3. Isotherm fitting parameter calculated using Langmuir and D-R isotherm models for cobalt and nickel extraction at $\mathrm{pH} 2.0 \pm 0.1$ on EBP-Si and $\mathrm{pH} 4.3 \pm 0.1$ on S950 at $21^{\circ} \mathrm{C}$ and $24 \mathrm{hr}$. contact time, using non-linear least squares fitting using SOLVER. Cobalt and nickel concentrations were constant at a ratio of 1:1.

\begin{tabular}{ccccc}
\hline Langmuir & \multicolumn{2}{c}{ EBP-Si } & \multicolumn{2}{c}{$\mathrm{S} 950$} \\
Constant & $\mathrm{Co}^{2+}$ & $\mathrm{Ni}^{2+}$ & $\mathrm{Co}^{2+}$ & $\mathrm{Ni}^{2+}$ \\
\hline $\log _{10} \mathrm{~K}_{\mathrm{L}}$ & 1.204 & 1.135 & 3.536 & 3.124 \\
$\mathrm{a}_{\mathrm{L}}$ & 60.26 & 47.42 & 3433.48 & 1331.61 \\
$\mathrm{q}_{\mathrm{m}}\left(\mathrm{mol} \cdot \mathrm{g}^{-1}\right)$ & 0.2652 & 0.2440 & 0.8354 & 0.8615 \\
$\mathrm{R}^{2}$ & 0.9257 & 0.9450 & 0.9193 & 0.9372 \\
\hline Dubinin-Radushkevich & \multicolumn{2}{c}{ EBP-Si }
\end{tabular}




\begin{tabular}{ccccc} 
Constant & $\mathrm{Co}^{2+}$ & $\mathrm{Ni}^{2+}$ & $\mathrm{Co}^{2+}$ & $\mathrm{Ni}^{2+}$ \\
\hline $\mathrm{B}_{\mathrm{D}}\left(\mathrm{x} 10^{-9}\right)$ & 8.547 & 9.566 & 2.8445 & 3.9054 \\
$\mathrm{q}_{\mathrm{D}}\left(\mathrm{mol} \cdot \mathrm{g}^{-1}\right)$ & 0.3072 & 0.3300 & 1.1700 & 1.3032 \\
$\mathrm{E}_{\mathrm{D}}\left(\mathrm{kJ} \cdot \mathrm{mol}^{-1}\right)$ & 7.648 & 7.230 & 13.258 & 11.315 \\
$\mathrm{R}^{2}$ & 0.9558 & 0.9661 & 0.9674 & 0.9886 \\
\hline
\end{tabular}

The calculated mean free energy, $E_{D}$, can be used to determine the type of adsorption; if $E_{D}$ falls in the range $8-16 \mathrm{~kJ} \mathrm{~mol}^{-1}$, adsorption is dominated by chemical ion exchange, whereas below $8 \mathrm{~kJ} \mathrm{~mol}^{-1}$, adsorption is dominated by physical forces. ${ }^{[45-}$ ${ }^{48]}$ The $E_{D}$ values for cobalt and nickel uptake are greater for S950 than for EBP-Si and are higher for cobalt than for nickel for both resins. In the case of S950, adsorption of $\mathrm{Co}(\mathrm{II})$ and $\mathrm{Ni}(\mathrm{II})$ is controlled by ion exchange, while adsorption by EBP-Si appears to be dominated by physisorption. This appears to directly contradict the results above which suggest that metals are adsorbed by EBP-Si via ion exchange. The D-R isotherm was chosen as it better represents a non-uniform surface and when the model parameters were calculated using the linear form of the D-R isotherm, the $E_{D}$ values were calculated at 9.170 and $9.113 \mathrm{~kJ} \mathrm{~mol}^{-1}$ for $\mathrm{Co}(\mathrm{II})$ and $\mathrm{Ni}(\mathrm{II})$ respectively. If an average of the non-linear and linear values are taken $\left(8.409\right.$ and $8.172 \mathrm{~kJ} \mathrm{~mol}^{-1}$ for $\mathrm{Co}$ (II) and $\mathrm{Ni}(\mathrm{II})$ respectively) then adsorption to EBP-Si occurs via ion exchange.

\section{Kinetic test}

Kinetic experiments were performed at $\mathrm{pH}$ values of 2 and 4.3 for H-EBP-Si and S950 as described above. Sorption of cobalt and nickel occurs rapidly on both resins, with the maximum uptake on EBP-Si occurring within an hour and on S950 within 2 hours. In the initial fitting of the kinetic data, it was assumed that the diffusion of the metal ion into the resin was the rate-determining step and that the counter diffusion of 
any anions and the reaction of the metal ion with the functional groups on the resin occur rapidly. ${ }^{[4]}$ Three models, film diffusion, particle diffusion and the Elovich model were fitted to the data and these are shown in Figure 7. If metal uptake was controlled by film diffusion, a plot of $-\ln \left(1-M_{A t} / M_{A 0}\right)$ versus time $t$ would be a straight line, ${ }^{[50]}$ where $M_{A t}$ and $M_{A 0}$ represent the aqueous concentrations of the metal at time $t$ and initially, respectively. Similarly, if particle diffusion dominated the kinetics, then a plot of $M_{R t}$ versus $\sqrt{ } t_{t}$ would yield a straight line ${ }^{[51]}$ where $M_{R t}$ is the metal resin concentration at time $t$. An attempt was also made to fit the data to the Elovich equation. ${ }^{[52]}$ It can be seen that in all three cases, the data does not fit a straight line through the origin. Therefore, it is reasonable to assume that diffusion of the metal ions onto both resins is not the rate-determining step. However, in the Elovich plot for the uptake by H-EBP-Si (Figure 7c), there is a degree of linearity that is often observed for systems in which the adsorbing surface is heterogeneous as could be expected from a functionalised silica. ${ }^{[53]}$ 


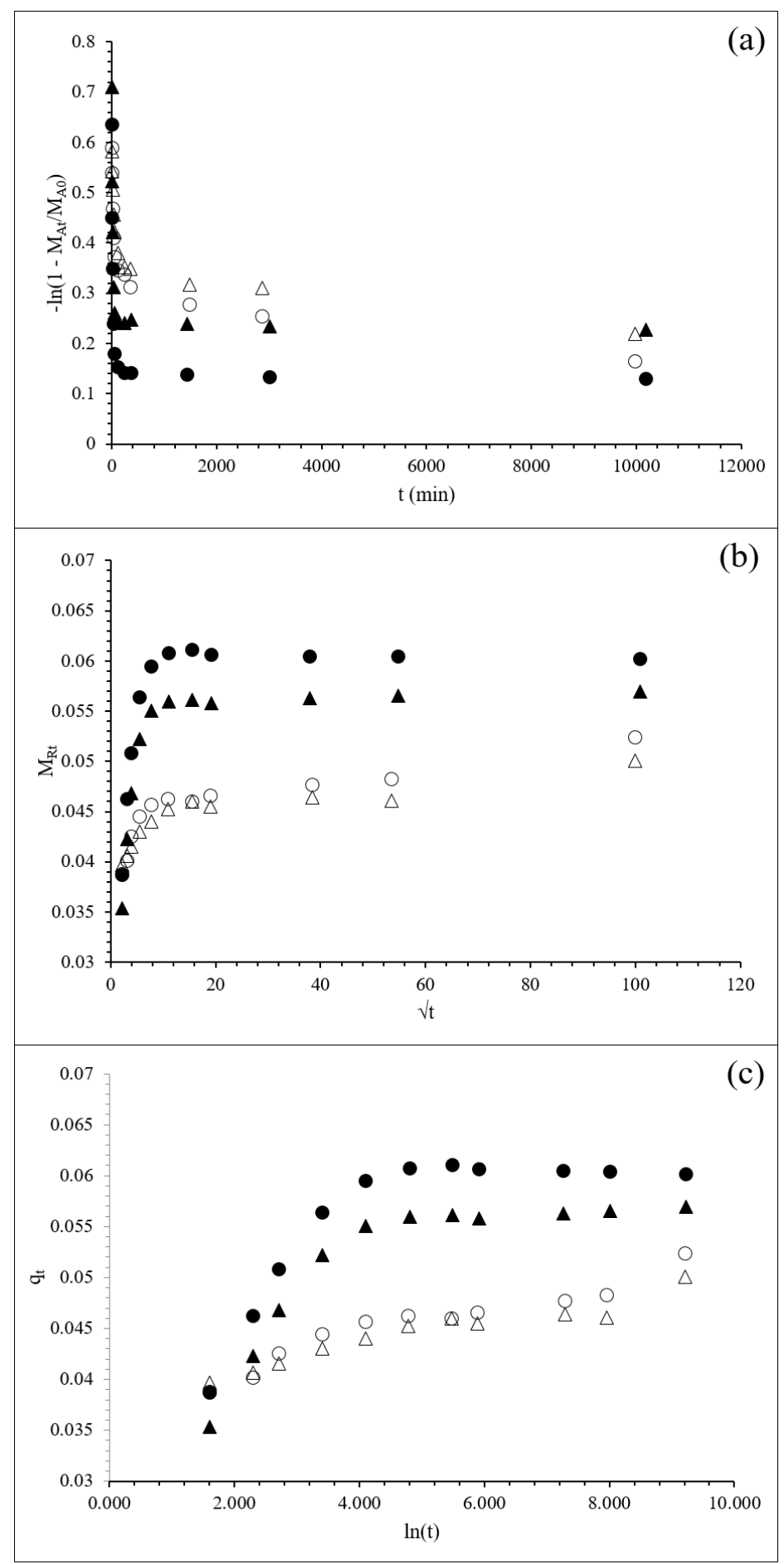

Figure 7. Kinetic fitting of cobalt and nickel uptake by EBP-Si and S950 using (a) film diffusion model, (b) pore diffusion model and (c) Elovich model at pH 2.0 and 4.3 respectively. Circles $=\mathrm{Co}^{2+}$ and triangles $=\mathrm{Ni}^{2+}$, open symbols $=\mathrm{EBP}-\mathrm{Si}$ and closed symbols $=\mathrm{S} 950$. 
Pseudo first and second order reaction kinetics were fitted to the data. The pseudo first order equation (Equation 7) and the pseudo second order equations (Equations 8-10) are shown below: ${ }^{[26,51-54]}$

$$
\begin{aligned}
& q_{t}=q_{e}\left(1-e^{-k_{1} t}\right) \\
& q_{t}=\frac{k_{2} q_{e}^{2} t}{1+k_{2} q_{e} t} \\
& t_{1 / 2}=\frac{1}{k_{2} q_{e}} \\
& h_{0}=k_{2} q_{e}^{2}
\end{aligned}
$$

Where $q_{t}$ and $q_{e}$ are the metal concentrations ( $\left.\mathrm{mol} \mathrm{g}^{-1}\right)$ at time $t$ (min) and at equilibrium, respectively, $k_{1}$ and $k_{2}\left(\mathrm{~g} \mathrm{~mol}^{-1} \mathrm{~min}^{-1}\right)$ are the pseudo first order and pseudo second order rate constants, respectively, $\mathrm{t}_{1 / 2}$ is the sorption half time (min) and $h_{0}$ is the initial adsorption rate $\left(\mathrm{mg} \mathrm{g}^{-1} \mathrm{~min}^{-1}\right)$. The parameters calculated are presented in Table 4. It can be seen from the $\mathrm{R}^{2}$ values that the data does not fit a pseudo-first order reaction mechanism. The pseudo second order data is shown in Figure 8. The rate constants determined for EBP-Si are much higher than for S950, nearly two and half times greater, and the sorption half-time for both resins occurs in minutes but uptake by EBP-Si is more rapid than S950. Due to the differences in structure, described previously, it seems apparent that while uptake is higher on S950 than EBP-Si, it takes longer for cobalt and nickel to access all the sites available for sorption. 


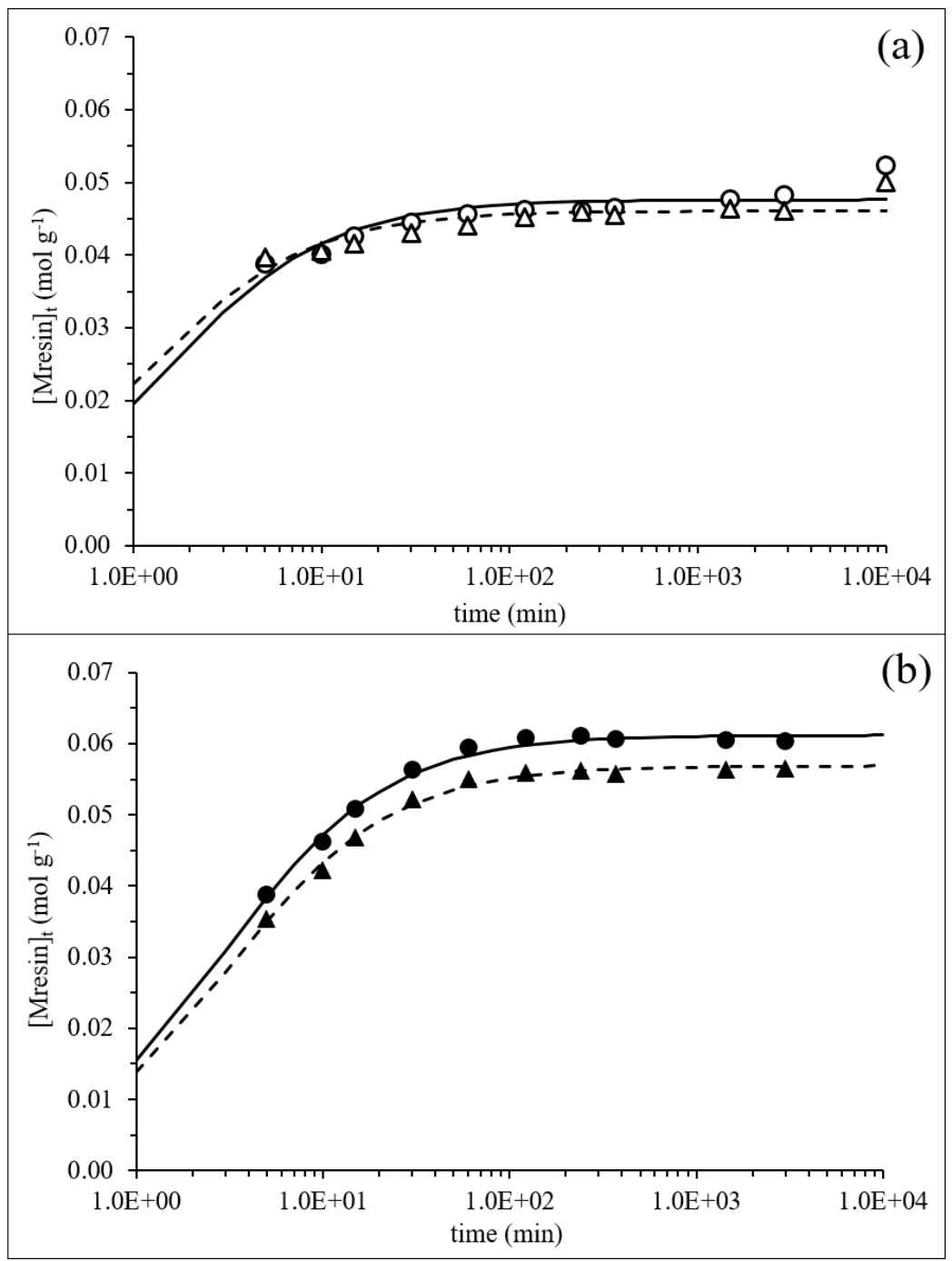

Figure 8: Uptake of cobalt and nickel as a function of time and pseudo-second order (PSO) kinetic fitting on (a) EBP-Si and (b) S950. Circles $=\mathrm{Co}^{2+}$ and triangles $=\mathrm{Ni}^{2+}$, black solid line $=\mathrm{Co}^{2+}$ PSO fitting, black dashed line $=\mathrm{Ni}^{2+}$ PSO fitting.

The overall superior fit of the pseudo-second-order model with the experimental data implies that the adsorption/desorption process, i.e. the chemical reaction of the metal ions with the chelating functionality of the extractants, is the rate-determining process,${ }^{[48]}$ much like chemisorption involving valence force through sharing or exchange of electrons between the functionality and heavy metal ions. ${ }^{[55]}$ This type of kinetic behaviour has been observed before in the uptake of $\mathrm{Co}(\mathrm{II})$ and $\mathrm{Ni}$ (II) on synthesized cross-linked poly[(aminopropyl)phosphonates where the fitting did not 
follow diffusion controlled models but produced a comprehensively superior pseudo second order model fit. ${ }^{[55]}$

Table 4. Pseudo-first order and pseudo-second order reaction kinetic parameters determined for uptake of $\mathrm{Co}$ and $\mathrm{Ni}$ at $\mathrm{pH} 2 \pm 0.1$ and $4.3 \pm 0.1$ for H-EBP-Si and S950, respectively. Cobalt and nickel concentrations were equal at $100 \mathrm{ppm}$ each.

\begin{tabular}{|c|c|c|c|c|}
\hline \multirow{2}{*}{$\begin{array}{c}\text { Pseudo-first order } \\
\text { Constant }\end{array}$} & \multicolumn{2}{|c|}{ EBP-Si } & \multicolumn{2}{|c|}{ S950 } \\
\hline & $\mathrm{Co}^{2+}$ & $\mathrm{Ni}^{2+}$ & $\mathrm{Co}^{2+}$ & $\mathrm{Ni}^{2+}$ \\
\hline$k_{1}\left(\mathrm{~g} \mathrm{~mol}^{-1} \mathrm{~min}^{-1}\right)$ & 0.31 & 0.38 & 0.17 & 0.16 \\
\hline $\mathrm{q}_{\mathrm{e}}\left(\mathrm{mol} \mathrm{g}^{-1}\right)$ & 0.0465 & 0.0451 & 0.0596 & 0.0553 \\
\hline$t_{1 / 2}(\min )$ & 2.249 & 1.810 & 4.075 & 4.238 \\
\hline $\mathrm{R}^{2}$ & 0.7365 & 0.7545 & 0.8945 & 0.8987 \\
\hline $\begin{array}{c}\text { Pseudo-second } \\
\text { order }\end{array}$ & \multicolumn{2}{|c|}{ EBP-Si } & \multicolumn{2}{|c|}{ S950 } \\
\hline Constant & $\mathrm{Co}^{2+}$ & $\mathrm{Ni}^{2+}$ & $\mathrm{Co}^{2+}$ & $\mathrm{Ni}^{2+}$ \\
\hline$k_{2}\left(\mathrm{~g} \mathrm{~mol}^{-1} \mathrm{~min}^{-1}\right)$ & 14.51 & 20.17 & 5.50 & 5.59 \\
\hline $\mathrm{q}_{\mathrm{e}}\left(\mathrm{mol} \mathrm{g}^{-1}\right)$ & 0.0476 & 0.0461 & 0.0612 & 0.0569 \\
\hline$t_{1 / 2}(\min )$ & 1.447 & 1.076 & 2.971 & 3.142 \\
\hline$h_{0}\left(\mathrm{~mol} \mathrm{~g}^{-1} \mathrm{~min}^{-1}\right)$ & 0.0329 & 0.0428 & 0.0206 & 0.0180 \\
\hline$R^{2}$ & 0.9830 & 0.9861 & 0.9982 & 0.9987 \\
\hline
\end{tabular}

\section{Conclusions}

The $\mathrm{pK}_{\mathrm{a}}$ values for a commercially available silica-based resin, EBP-Si, were determined via acid base titration and three values were found at $4.22( \pm 0.04), 6.38( \pm$ 0.06 and $6.46( \pm 0.03)$. It is suggested that these values represent the silanol group on 
the silica support material and the phosphonate group of the attached ligand, with the two values at 6.38 and 6.46 representing heterogeneity of the functionalised surface. The uptake of cobalt and nickel by this resin was also investigated and compared to S950, a macroporous polystyrene resin crosslinked with DVB. It was found that both resins perform well at weakly acidic $\mathrm{pH}$ values. An analysis of the $\mathrm{pH}$ effect, metal isotherm and kinetic data suggests that the mechanism of uptake proceeds via ion exchange. There is also evidence of acid dissociation occurring.

Metal isotherm experiments showed that the uptake of cobalt and nickel increases up to a maximum value corresponding to the saturation of the available surface sites. Langmuir and D-R isotherms were fitted to the data and their respective parameters determined. The $\mathrm{D}-\mathrm{R}$ isotherm provided a better fit, probably due to its ability to more accurately describe uptake onto a heterogeneous surface. The maximum sorption capacity of S950 was found to be nearly four and a half times greater than that of EBP-Si, most likely due to the differences in structure. However, kinetic data suggested that the uptake onto EBP-Si was much more rapid, about two and half times faster. The rate-limiting step was found to be the interaction between the metal and the chelating ligand rather than diffusion.

This initial study suggests that EBP-Si may be useful in removing metal species from aqueous waste streams. Experiments are continuing to investigate its ability to remove these and other problematic species, including the effect of high ionic strength on metal uptake in both static and dynamic column studies.

Under normal circumstances, ion exchange resins are reused after the metal is stripped from the resin. However, we have not investigated resin stripping as this is an initial study into the feasibility of using silica-based resins as precursor materials in the formation of glass-based waste forms. Therefore, there would be no need to strip the 
metals as the metal-loaded material would be combined with other ingredients and heated to form glass. Experiments are currently underway investigating the direct conversion of the loaded material into a glass-based waste form and its subsequent ability to retain those species under standard leaching conditions.

Acknowledgements:

Special thanks to Claire Corkhill and Clare Thorpe for their help with ICP-OES analysis and Mark Jones for his assistance with AAS.

This work was supported by the Engineering and Physical Sciences Research Council through the UK Korea Civil Nuclear Energy program grant EP/M026558/1 Silicate Nanoparticles for Extraction of Radionuclides (SINNER).

References:

[1] Forstner, U.; William, G. T. W. (1983) Metal Pollution in the Aquatic Environment; Springer-Verlag: Berlin.

[2] Rengaraj, S.; Moon, S. H. (2002) Kinetics of adsorption of Co(II) removal from water and wastewater by ion exchange resins. Water Research, 36: 1783-1793.

[3] Sofińska-Chmiel, W.; Kołodyńska, D. (2016) Purolite S940 and Purolite S950 in heavy metal ions removal from acidic streams. Separation Science and Technology, 51: 2528-2538.

[4] Outola, P.; Leinonen, H.; Ridell, M.; Lehto, J. (2001) Acid/base and metal uptake properties of chelating and weak base resins. Solvent Extraction and Ion Exchange, 19: 743-756.

[5] Rosenberg, E.; Pinson, G.; Tsosie, R.; Tutu, H.; Cukrowska, E. (2016) Uranium remediation by ion exchange and sorption methods: A critical review. Johnson Matthey Technology Review, 60: 59-77.

[6] Mendes, F. D.; Martins, A. H. (2005) Recovery of nickel and cobalt from acid leach pulp by ion exchange using chelating resin. Minerals Engineering, 18: 945-954.

[7] Sarkar, A. R.; Datta, P. K.; Sarkar, M. (1996) Sorption recovery of metal ions using silica gel modified with salicylaldoxime. Talanta, 43: 1857-1862. 
[8] Hanzel, R.; Rajec, P. (2000) Sorption of cobalt on modified silica gel materials. Journal of Radioanalytical and Nuclear Chemistry, 246: 607-615.

[9] Xie, F.; Lin, X.; Wu, X.; Xie, Z. (2008) Solid phase extraction of lead (II), copper (II), cadmium (II) and nickel (II) using gallic acid-modified silica gel prior to determination by flame atomic absorption spectrometry. Talanta, 74: 836-843.

[10] Zainol, Z.; Nicol, M. J. (2009) Ion-exchange equilibria of $\mathrm{Ni}^{2+}, \mathrm{Co}^{2+}, \mathrm{Mn}^{2+}$ and $\mathrm{Mg}^{2+}$ with iminodiacetic acid chelating resin Amberlite IRC 748. Hydrometallurgy, 99: 175-180.

[11] Sadeghi, S.; Sheikhzadeh, E. (2009) Solid phase extraction using silica gel modified with murexide for preconcentration of uranium(VI) ions from water samples. Journal of Hazardous Materials, 163: 861-868.

[12] Schulz, W. W.; Horwitz, E. P. (1994) Chemical Pretreatment of Nuclear Waste for Disposal; Springer: New York.

[13] Alexandratos, S. D. (2009) Ion-exchange resins: A retrospective from Industrial and Engineering Chemistry Research. Industrial and Engineering Chemistry Research, 48: 388-398.

[14] Hubicki, Z.; Kołodyńska, D. (2012) Selective removal of heavy metal ions from waters and waste waters using ion exchange methods. In: Ion Exchange Technologies; InTech.

[15] Ritcey, G. M.; Ashbrook, A. W. (1984) Solvent extraction: Principles and applications to process metallurgy; Elsevier: Amsterdam.

[16] De, A. K.; Khopkar, S. M.; Chalmers, R. A. (1970) Solvent extraction of metals; Van Nostrand Reinhold: London.

[17] Pepper, S. E.; Borkowski, M.; Richmann, M. K.; Reed, D. T. (2010) Determination of ferrous and ferric iron in aqueous biological solutions. Analytica Chimica Acta, 663: 172-177.

[18] Harland, C. E. (1994) Ion exchange: Theory and practice: The Royal Society of Chemistry: Cambridge.

[19] Riegel, M.; Tokmachev, M.; Hoell, W. H. (2008) Kinetics of uranium sorption onto weakly basic anion exchangers. Reactive and Functional Polymers, 68:1072-1080. 
[20] Jal, P. K.; Patel, S.; Mishra, B. K. (2004) Chemical modification of silica surface by immobilization of functional groups for extractive concentration of metal ions. Talanta, 62: 1005-1028.

[21] Goswami, A.; Singh, A. K. (2002) Enrichment of iron(III), cobalt(II), nickel(II) and copper(II) by solid-phase extraction with 1,8-dihydroxyanthraquinone anchored to silica gel before their determination by flame atomic absorption spectroscopy. Analytical and Bioanalytical Chemistry, 374: 554-560.

[22] Fernandez, M. A.; Carta, G. (1996) Characterization of protein adsorption by composite silica-polyacrylamide gel anion exchangers I. Equilibrium and mass transfer in agitated contactors. Journal of Chromatography A, 746: 169-183.

[23] Sahni, S. K.; Van Bennekom, R.; Reedijk, J. (1985) A spectral study of transitionmetal complexes on a chelating ion-exchange resin containing aminophosphonic acid groups. Polyhedron, 4: 1643-1658.

[24] Deepatana, A.; Valix, M. (2006) Recovery of nickel and cobalt from organic acid complexes: Adsorption mechanisms of metal-organic complexes onto aminophosphonate chelating resin. Journal of Hazardous Materials, B137: 925933.

[25] Kiefer, R.; Höll, W. H. (2001) Sorption of heavy metals onto selective ionexchange resins with aminophosphonate functional groups. Industrial and Engineering Chemistry Research, 40: 4570-4576.

[26] Alyüz, B.; Veli, S. (2009) Kinetics and equilibrium studies for the removal of nickel and zinc from aqueous solutions by ion exchange resins. Journal of Hazardous Materials, 167: 482-488.

[27] Aşçi, Y.; Kaya, S. (2014) Removal of cobalt ions from water by ion-exchange method. Desalination and Water Treatment, 52: 267-273.

[28] International Atomic Energy Authority (2002) Application of ion exchange processes for the treatment of spent ion exchangers. Technical Report Series No. 408, IAEA: Vienna.

[29] Kim, K.; Kim, K.; Choi, M.; Son, S. H.; Han, J. E. (2012) Treatment of ion exchange resins used in nuclear power plants by super- and sub-critical water oxidation - A road to commercial plant from bench-scale facility. Chemical Engineering Journal, 189-190:213-221. 
[30] Hamodi, N.; Papadopoulou, K.; Lowe, T.; Abram, T. (2012) Thermal analysis and immobilisation of spent ion exchange resin in borosilicate glass. New Journal of Glass and Ceramics, 2: 111-120.

[31] Wang, J.; Wan, Z. (2015) Treatment and disposal of spent radioactive ionexchange resins produced in the nuclear industry. Progress in Nuclear Energy, 78: 47-55.

[32] Schofield, J. M.; Swanton, S. W.; Farahani, B.; Myatt, B. J.; Heath, T. G.; Burrows, S. E.; Holland, D.; Moule, A.; Brigden, C. T.; Farnan, I. (2016) Experimental studies of the chemical durability of UK HLW and ILW glasses. Interim Progress Report. Nuclear Decommissioning Authority.

[33] Jarvis, N. V.; Wagener, J. M. (1994) Mechanistic studies of chelating resins using two-phase potentiometry. Talanta, 41: 747-754.

[34] Zekany, L.; Nagypal, I. (1985) PSEQUAD: A comprehensive program for the evaluation of potentiometric and/or spectrophotometric equilibrium data using analytical derivatives. In Computational methods for the determination of formation constants, Plenum Press: New York.

[35] Ho, Y. S.; Porter, J. F.; McKay, G. (2002) Equilibrium isotherm studies for the sorption of divalent metal ions onto peat: copper, nickel and lead single component systems. Water, Air and Soil Pollution, 141: 1-33.

[36] Jencks, W. P.; Regenstein, J. (1975) Ionization constants of acids and bases. In Handbook of biochemistry and molecular biology, CRC Press: Cleveland.

[37] Ogden, M. D.; Moon, E. M.; Wilson, A.; Pepper, S. E. (2017) Application of chelating weak base resin Dowex M4195 to the recovery of uranium from mixed sulfate/chloride media. Chemical Engineering Journal, 317: 80-89.

[38] Leung, K.; Nielsen I. M. B.; Criscenti, L. J. (2009) Elucidating the bimodal acidbase behaviour of the water-silica interface from first principles. Journal of the American Chemical Society, 131: 18358-18365.

[39] Tkac, P.; Vendegrift, G. F.; Lumetta, G. J.; Gelis, A. V. (2012) Study of the interaction between HDEHP and CMPO and its effect on the extraction of selected lanthanides. Industrial and Engineering Chemistry Research, 51: 10433-10444.

[40] Foo, K. Y.; Hameed, B. H. (2010) Insights into the modelling of adsorption isotherm systems. Chemical Engineering Journal, 156: 2-10. 
[41] Itodo, A. U.; Itodo, H. U. (2010) Sorption energies estimation using DubininRadushkevich and Temkin adsorption isotherms. Life Science Journal, 7: 31-39.

[42] Billo, E. J. (2001) EXCEL® for chemists: a comprehensive guide, $2^{\text {nd }}$ edition; Wiley-VCH: New York.

[43] Arakaki, L. N. H.; Nunes, L. M.; Simoni, J. A.; Airoldi, C. (2000) Ethyleneimine anchored on thiol-modified silica gel surface - Adsorption of divalent cations and calorimetric data. Journal of Colloid and Interface Science, 228: 46-51.

[44] Jain, M., Garg, V. K., Kadirvelu, K. (2009) Chromium (VI) removal from aqueous system using Helianthus annuus (sunflower) stem waste. Journal of Hazardous Materials, 162: 365-372.

[45] Jin, T.; Yuan, W.; Xue, Y.; Wei, H.; Zhang, C.; Li, K. (2017) Co-modified MCM41 as an effective adsorbent for levofloxacin removal from aqueous solution: optimization of process parameters, isotherm and thermodynamic studies. Environmental Science and Pollution Research, 24: 5238-5248.

[46] Langeroodi, N. S. (2017) Equilibrium and kinetics of biosorption of oxalic acid by wheat straw. Russian Journal of Physical Chemistry B, 11: 318-323.

[47] Gilca, E.; Maicaneanu, A,; Petru, I. (2014) Removal of zinc ions as zinc chloride complexes from strongly acidic aqueous solutions by ion exchange. Central European Journal of Chemistry, 12: 821-828.

[48] Qiu, H.; Lv, L.; Pan, B.; Zhang, Q.; Zhang, W.; Zhang, Q. (2009) Critical review in adsorption kinetic models. Journal of Zhejiang University SCIENCE A, 10: 716724.

[49] Tarawoui, T.; Young, E. (2015) Intraparticle and liquid film diffusion studies on the adsorption of $\mathrm{Cu}^{2+}$ and $\mathrm{Pb}^{2+}$ ions from aqueous solution using powdered cocoa pod (Theobroma cacao). International Research Journal of Engineering and Technology, 2: 236-243.

[50] Maksin, D. D.; Kljajević, S. O.; Đolić, M. B.; Marković, J. P.; Ekmeščić, B. M.; Onjia, A. E.; Nastasović, A. B. (2012) Kinetic modelling of heavy metal sorption by vinyl pyridine based copolymer. Hemijska Industrija, 66: 795-804.

[51] Maiyalagan, T.; Karthikeyan, S. (2013) Film-pore diffusion modelling for sorption of azo dye on to exfoliated graphitic nanoplatelets. Indian Journal of Chemical Technology, 20: 7-14. 
[52] Plazinski, W.; Rudzinski, W.; Plazinska, A. (2009) Theoretical models of sorption kinetics including a surface reaction mechanism: A review. Advances in Colloid and Interface Science, 152: 2-13.

[53] Karthikeyan, S.; Sivakumar, B.; Sivakumar, N. (2010) Film and pore diffusion modelling for adsorption of reactive red 2 from aqueous solution on to activated carbon prepared from bio-diesel industrial waste. E-journal of Chemistry, 7: S175-S184.

[54] Zhang, H.; Tang, Y.; Cai, D.; Liu, X.; Wang, X.; Huang, Q.; Yu, Z. (2010) Hexavalent chromium removal from aqueous solution by algal bloom residue derived activated carbon: Equilibrium and kinetic studies. Journal of Hazardous Materials, 181: 801-808.

[55] Ali, S. A.; Kazi, I. W.; Ullah, N. (2015) New chelating ion-exchange resin synthesized via the cyclopolymerization protocol and its uptake performance for metal ion removal. Industrial and Engineering Chemistry Research, 54: 96899698. 